\title{
Comment on the intravenous tranexamic acid use in revision total joint arthroplasty
}

This article was published in the following Dove Press journal:

Drug Design, Development and Therapy

Jieyu $\mathrm{He}$

Youshuo Liu

Department of Geriatrics, Second Xiangya Hospital, Central South University, Changsha 4I00II, China

\section{Dear editor}

Kuo et al thoroughly evaluated the safety and efficacy of intravenous tranexamic acid in revision total joint arthroplasty (TJA) via aspects of blood loss and transfusion, events of venous thromboembolism. ${ }^{1}$ We consider application of this drug of great value in revision TJA. However, we would like to address several concerns related to this meta-analysis.

First, the conclusion of no increased risk of venous thromboembolism was drawn through assessment of five studies, according to the description in the context, yet data of only two studies were extracted in Figure 6, in the form of a forest plot. We carefully read the other five studies selected in this meta-analysis, and found three more of them that contained data of thromboembolic events. ${ }^{2-4}$ Two of them showed favorable results for no related event occurrence, ${ }^{2,3}$ and the third found increased incidence of thrombotic complications without statistical significance $(P=0.3){ }^{4}$ We suggest these results should be included in the analysis, so as to raise the reliability of this conclusion.

Second, there were some deficiencies in the literature search. Only three electronic databases (PubMed, Scopus, and Cochrane Central Register of Controlled Trials) were systematically searched. The small number of studies included might be a limitation of this meta-analysis. Since most of the investigators came from China, a more comprehensive search should also include Chinese databases, such as CBM on Disc and CNKI.

We appreciate the investigators' contribution in supplying us with an excellent safety and efficacy evaluation of intravenous tranexamic acid in revision TJA. If possible, we hope the investigators can make proper revisions to this meta-analysis to make it more credible. Moreover, for the disadvantages of unavoidable risk of bias caused by the limited number of qualified clinical trials or retrospective studies, further prospective randomized controlled trials are required, just as the investigators pointed out in the conclusion.

\section{Disclosure}

The authors report no conflicts of interest in this communication.

\section{References}

1. Kuo FC, Lin PY, Wang JW, Lin PC, Lee MS, Chen AF. Intravenous tranexamic acid use in revision total joint arthroplasty: a meta-analysis. Drug Des Devel Ther. 2018;12:3163-3170.

2. Aguilera X, Videla S, Almenara M, Fernandez JA, Gich I, Celaya F. Effectiveness of tranexamic acid in revision total knee arthroplasty. Acta Orthop Belg. 2012;78(1):68-74. 
3. Park KJ, Couch CG, Edwards PK, Siegel ER, Mears SC, Barnes CL. Tranexamic Acid Reduces Blood Transfusions in Revision Total Hip Arthroplasty. J Arthroplasty. 2016;31(12):2850-2855.e1.
4. Kazi HA, Fountain JR, Thomas TG, Carroll FA. The effect of bolus administration of tranexamic acid in revision hip arthroplasty. Hip Int. 2012;22(6):615-620. 


\section{Authors' reply \\ Feng-Chih Kuo' \\ Pao-Yen Lin ${ }^{2}$ \\ Jun-Wen Wang' \\ Po-Chun Lin' \\ Mel S Lee' \\ Antonia F Chen ${ }^{3}$ \\ 'Department of Orthopaedic Surgery, Kaohsiung Chang Gung Memorial Hospital, College of Medicine, Chang Gung University, Kaohsiung, Taiwan; ${ }^{2}$ Department of Psychiatry, Kaohsiung Chang Gung Memorial Hospital, College of Medicine, Chang Gung University, Kaohsiung, Taiwan; ${ }^{3}$ Department of Orthopaedic Surgery, Brigham and Women's Hospital, Harvard Medical School, Boston, MA, USA}

Correspondence: Antonia F Chen

Department of Orthopaedic Surgery, Brigham and Women's Hospital, Harvard Medical School, 75 Francis Street, Boston, MA, USA

Tel +l 6175255935

Fax +I 6172645226

Email afchen@bwh.harvard.edu

\section{Dear editor}

We read the letter from $\mathrm{He}$ and Liu in response to our recently published article entitled "Intravenous tranexamic acid use in revision total joint arthroplasty: a meta-analysis" with interest.

$\mathrm{He}$ and Liu were concerned that five studies were included in the manuscript regarding the assessment of venous thromboembolism (VTE), but only two were listed in the forest plot (Figure 6). However, three studies did not report VTE events in their articles. ${ }^{2-4}$ When these results were analyzed using our statistical software (Comprehensive Meta-Analysis version 2; Biostat, Englewood, NJ, USA), these studies were automatically excluded, since they had zero events in both arms. This is consistent with the standardpractice recommendation from the Cochrane handbook, ${ }^{5}$ where trials with zero events in both arms are not included in the meta-analysis, as odds ratios are calculated. A study from Kazi et $\mathrm{al}^{6}$ was not included in the analysis for the following reasons: 1) the authors did not provide the number of true episodes of VTE events in their study, 2) the evaluation of thromboembolic complications was diagnosed based on clinical suspicion, not routine duplex scans or venography exam, which might have resulted in a higher but inaccurate incidence of thromboembolic complications, and 3) when we contacted the author to obtain the raw data, they could not provide it to us because the data had expired the 6-year window and been destroyed due to patient confidentiality and data protection.

He and Liu criticized that only three databases (PubMed, Scopus, and Cochrane Central Register of Controlled Trials) were used in the systematic search, and suggested that we should include Chinese databases, such as CBM on Disc and CNKI. We then expanded the search to include the following databases during the study period: Ovid, Embase, Google Scholar, CBM on Disc, and CNKI. However, we did not find any additional English literature according to the inclusion and exclusion criteria listed in our study, and thus our conclusion is unchanged.

In conclusion, we are grateful to Drs He and Liu for their interest in our study. We want to thank them for sharing their knowledge with us and other readers to make this study and future studies better.

\section{Disclosure}

The authors report no conflicts of interest in this communication.

\section{References}

1. Kuo FC, Lin PY, Wang JW, Lin PC, Lee MS, Chen AF. Intravenous tranexamic acid use in revision total joint arthroplasty: a meta-analysis. Drug Des Devel Ther. 2018;12:3163-3170.

2. Gill JB, Chase E, Rosenstein AD. The use of tranexamic acid in revision total hip arthroplasty: a pilot study. Curr Orthop Pract. 2009;20(2): $152-156$.

3. Aguilera X, Videla S, Almenara M, Fernandez JA, Gich I, Celaya F. Effectiveness of tranexamic acid in revision total knee arthroplasty. Acta Orthop Belg. 2012;78(1):68-74.

4. Park KJ, Couch CG, Edwards PK, Siegel ER, Mears SC, Barnes CL. Tranexamic acid reduces blood transfusions in revision total hip arthroplasty. J Arthroplasty. 2016;31(12):2850-2855.e1.

5. Higgins JP, Green S, editors. Cochrane Handbook for Systematic Reviews of Interventions. Version 5.1.0 [updated March 2011]. Cochrane Collaboration, 2011. Available from: http://training.cochrane.org/handbook. Accessed November 25, 2018.

6. Kazi HA, Fountain JR, Thomas TG, Carroll FA. The effect of bolus administration of tranexamic acid in revision hip arthroplasty. Hip Int. 2012;22(6):615-620. 
Dove Medical Press encourages responsible, free and frank academic debate. The content of the Drug Design, Development and Therapy 'letters to the editor' section does not necessarily represent the views of Dove Medical Press, its officers, agents, employees, related entities or the Drug Design, Development and Therapy editors. While all reasonable steps have been taken to confirm the content of each letter, Dove Medical Press accepts no liability in respect of the content of any letter, nor is it responsible for the content and accuracy of any letter to the editor.

\section{Publish your work in this journal}

Drug Design, Development and Therapy is an international, peerreviewed open-access journal that spans the spectrum of drug design and development through to clinical applications. Clinical outcomes, patient safety, and programs for the development and effective, safe, and sustained use of medicines are the features of the journal, which

has also been accepted for indexing on PubMed Central. The manuscript management system is completely online and includes a very quick and fair peer-review system, which is all easy to use. Visit http://www.dovepress.com/testimonials.php to read real quotes from published authors.

Submit your manuscript here: http://www.dovepress.com/drug-design-development-and-therapy-journal 